\author{
TRABALHO DO DEPARTAMENTO DE TECNICA CIRURGICA E CIRURGIA \\ EXPERIMENTAL \\ Direţor: Prof. E. VASCONCELLOS
}

\title{
AFECÇÕES CIRURGICAS E CIRURGIA DOS VASOS SANGUINEOS
}

\author{
EDGARD PINTO DE SOUZA - GABRIEL BOTELHO
}

- O estudo das afecções cirurgicas dos vasos sanguineos constitue um dos mais vastos capitulos da patologia, e como tal iniciaremos o assunto com um apanhado geral sobre a questão e em seguida abordaremos principalmente no que diz respeito á técnica operatoria, algumas afecções cirurgicas dos vasos.

Vejamos em primeiro lugar a Histo-arquitetura dos vasos:

\section{I - HISTO-ARQUITETURA DAS ARTERIAS}

As paredes arteriaes compõem-se essencialmente de 3 camadas concentricas, ordinariamente chamadas tụnicas, que se distinguem conforme sua situação, em tunica interna, tunica media e tunica externa: a tunica interna é de natureza endotelial; a media é musculoelastica; e a externa ou adventicia é conjuntiva. Estas 3 tunicas cada uma com seus elementos proprios, se encontram indistintamente em todas as arterias. Mas elas variam muito segundo o volume da arteria. E pois conveniente examinar separadamente: $1 .^{\circ}$ ) as pequenas arterias ou arteriolas; $2 .^{\circ}$ ) as arterias de medio calibre; $3^{\circ}$ ) as grandes arterias.

1. ${ }^{\circ}$ ) Arteriolas - (Fig. 1). Compõem-se de 3 camađas:

a) Tunica interna - E formada por celulas endoteliaes as quais repousam em uma fina membrana anhista, a vitrea (2 fig. 1).

b) Tunica media - Tem por elementos essenciais as fibras musculares lisas (3 fig. 1), por elemento acessorio uma fina lamina elastica, designada lamina elastica interna ou limitante elastica interna (1 fig. 1). 
c) Tunica ixtcrna - Tambem chamada adventicia, é formada nas pequenas arteriolas, exclusivamente por celulas conjuntivas; á

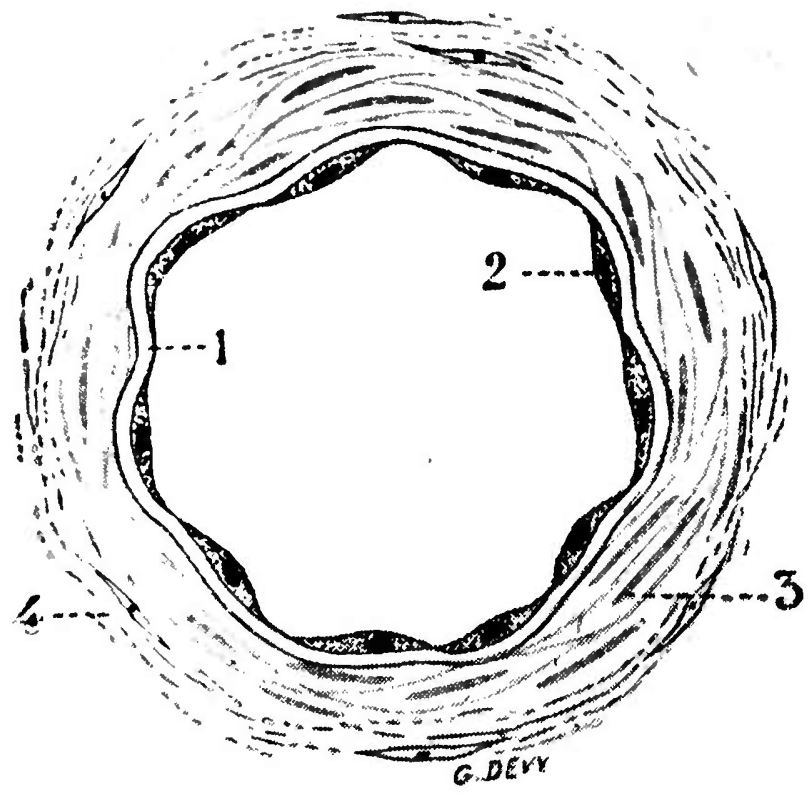

Fig. 1

Corte transversal de uma arteríola. 1, lâmina elástica interna ou limitante elástica int. 2, endotélio. 3, fibras musculares lisas. 4, adventícia com suas fibras e células conjuntivas.

estas se juntam nas arteriolas mais volumosas, um certo numero de fibrilas conjuntivas e elasticas extremamente finas (4 fig. 1).

$\left.2 .^{\circ}\right)$ Arterias de medio calibre ou arterias do tipo muscular - As arterias de medio calibre, tais como a humeral, a radial a cubital, a femural, as tibiais anterior e posterior etc.... têm como caracteristica principal, o desenvolvimento consideravel dos elementos musculares na tunica media. Daí o nome de arterias do tipo muscular.

A) Tunica interna - (A, fig. 2) : - Apresenta, como nas arteriolas, um endotelio repousando sobre uma fina membrana vitrea (1 e 2, fig. 2). Externamente ao endotelio e sua vitrea, aparece porem uma nova camada, a chamada endarteria ou camada estriada ( 3 , fig. 2) ; esta é de natureza conjuntivo-elastica, isto é, formada por celulas e fibras conjuntivas, ás quais se junta um certo numero de fibrilas elasticas.

B) Tunica media - E quasi que exclusivamente constituida por fibras musculares lisas (B, fig. 2). Estas fibras se agrupam em feixes mais ou menos numerosos, que abraçam a arteria a maneira de um anel, e acham-se unidas umas as outras, por elementos de tecido conjuntivo: fibras e celulas conjuntivas. Á estes elementos interfasciculares vem se ajuntar fibras elasticas, (b, fig. 2). Concluin. do: a tunica media das arterias de medio calibre se compóe de um reticulo conjuntivo-elastico - o elemento principal - em cujas malhas 
se encontram as fibras musculares - o elemento acessorio - Existe egualmente como nas arteriolas, uma limitante elastica interna, egualmente constituida (a, fig. 2).

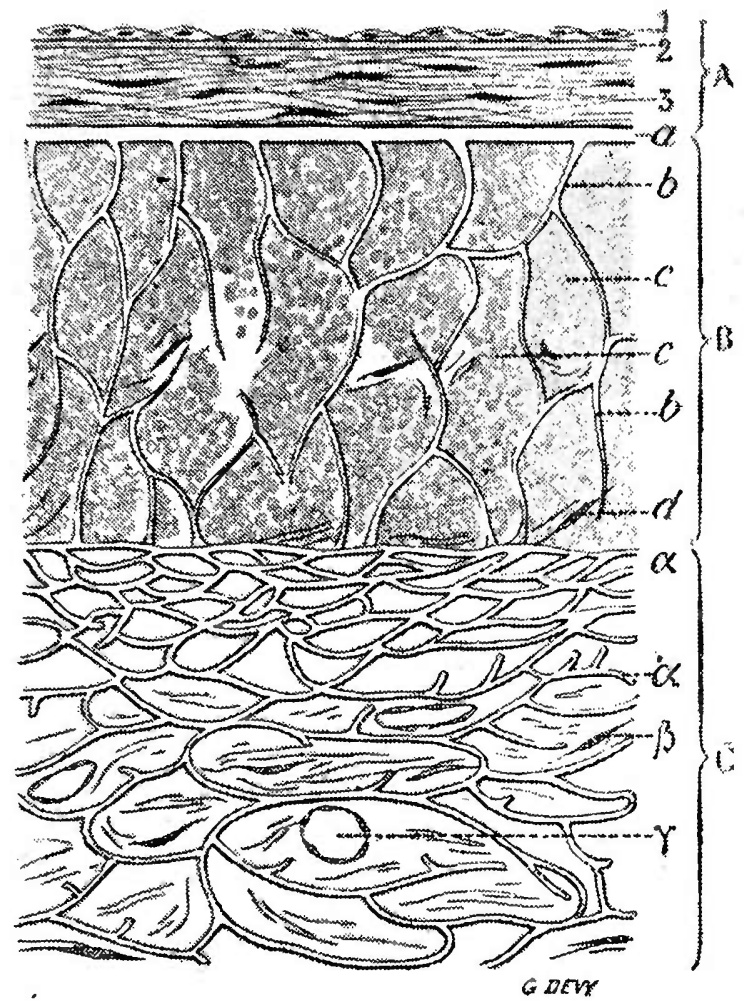

FIG. 2

Arteria do tipo muscular cortelongitudinal. A, tunica interna com: 1 , endotelio; 2 , vitrea; 3 , endarteria. $B$, tunica media com: a, limitante elastica interna; b, traves da rede elastica; $c$, feixes musculares; $d$ celulas conjuntivas. $\mathrm{C}$, tunica externa ou adventicia com: traves da rede elastica, se condensando em

alfa para formar a limitante elástica externa.

C) Tunica externa - Tambem conhecida por adventicia (C, fig. 2), se compõe essencialmente dé feixes conjuntivos aos quais se juntam fibras elasticas anastomosadas em rêde. No limite da tunica media com a externa, ha um adensamento das fibras elasticas, que se costuma designar por limitante elastica externa (alpha, fig. 2) a qual porém nem sempre é bem evidencialvel. Por sua superficie externa, a adventicia é muito mal delimitada. Ela se confunde com efeito, sem linha de demarcação bem nitida, com o tecido conjuntivo periarterial.

3. ) Arterias de grande calibre ou arterias de tipo elastico - São representadas pela aorta, o tronco da pulmonar, o tronco braquio-cefalico, as sub-clavias, as carotidas primitivas, etc. Elas tem de particular, a predominancia, na tunica media, de tecido elastico. Daí o nome de arterias do tipo elastico. 
Apresentam histologicamente, como as arterias de medio-calibre, 3 camadas, a interna, a media e a externa (A, B, C, fig. 3). Diferenciam-se das arterias do tipo anterior principalmente pela camada media, que é predominantemente elastica em lugar de muscular. A endarteria na camada interna diferencia-se egualmente em muito da en-

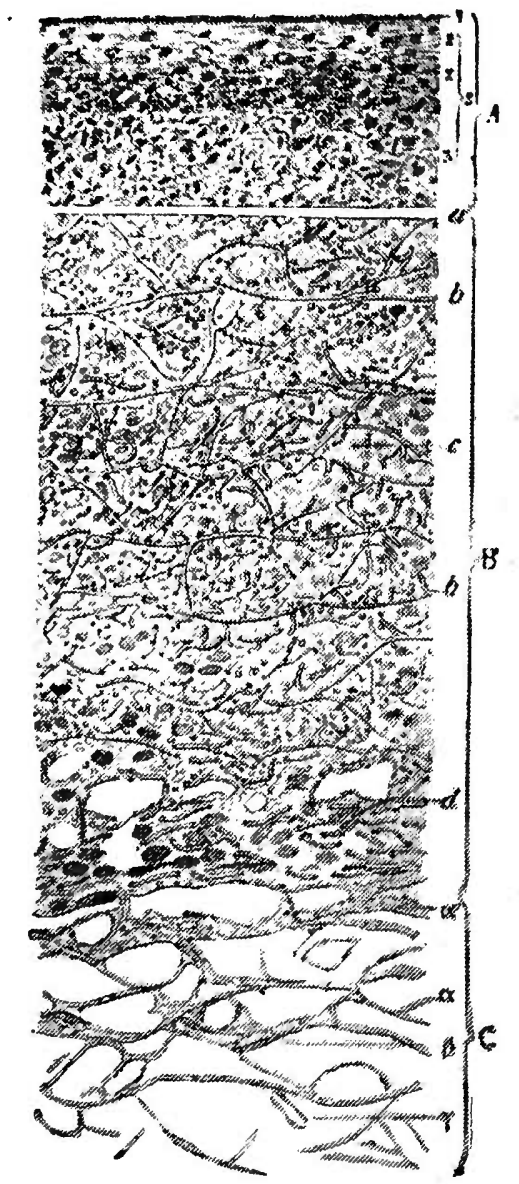

Frg. 3

Arteria do tipo elastico (corte longitudinal da aorta toraxica). A, tunica interna, com: 1 , endotelio repousando sobre sua vitrea; 2 , e 2" andar interno $\mathrm{e}$ andar externo da camada mucosa; 3, camada estriada. B, tunica media, com: a, limitante elastica interna; b, b, membranas elasticas; c, feixes musculares; d, celu. las conjuntivas. C, tunica externa ou adventicia com: limitante elastica externa; celulas do tecido conjuntivo; vasos.

darteria das arterias de calibre medio; tal diferenciação porem não nos interessa no momento.

Como vemos, o tecido elastico domina em muito, na origem do sistema arterial; pelo contrario, o elemento muscular predomina nas paredes das arterias de medio e pequeno calibre bem como nas arte- 
riolas que precedem os capilares. Quando um tronco vascular se divide, a soma das luzes dos 2 ramos de bifurcação, é sempre mais forte que a luz do tronco primitivo, de maneira que a capacidade do sistema, aumenta à medida que se distancía do tronco aortico. O conjunto do sistema arterial apresenta-se pois com uma fórma cônica. $\mathrm{O}$ grafico

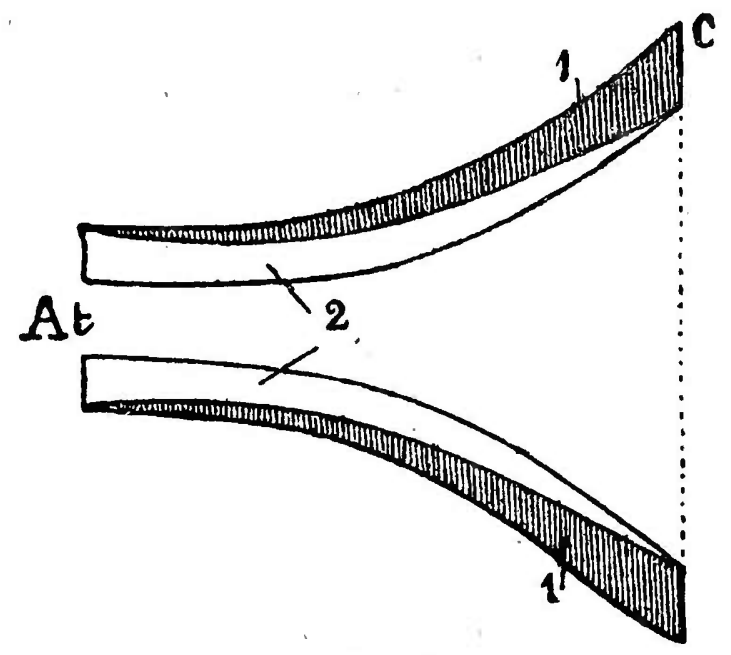

FIG. 4

Esquema da distribuiçāo elastico-muscular no sistema arterial. Proporção na qual o elemento elastico e o muscular entram na composição da parede do cone arterial, desde o vertice At até a sua base CC. 1,1 elemento muscular. 2 elemento elastico.

da fig. 4 representa o cone arterial ; a porção escura (1.) representa o elemento muscular, e a porção em branco o elemento elastico (2). Fica assim muito bem evidenciado que o tecido elastico excasseia á medida que se distancia da aorta, o inverso se verificando com o tecido muscular.

\section{II - HISTO-ARQUITETURA DAS VEIAS}

Se existe um tipo uniforme de constituição das arterias o mesmo não se nota com as veias. Evidentemente estas divergencias estruturais residem nas adatações funcionais, e neste particular Renaut distingue entre as grandes veias, 2 tipos: as veias propulsivas, em que encontramos uma grande quantidade de fibras musculares lisas, e que poderiam ser comparadas com as arterias do tipo muscular; as veias receptoras, que na verdade nada mais são do que simples reservatorios, em que o sistema muscular liso entra em pequena proporção. Um grande numero de A.A., com o fito de estabelecer uma simetria entre as arterias e as veias, admitem, nestas ultimas, uma tunica interna, uma media e outra externa. Destas 3, sómente a primeira é que tem limites nitidos e precisos; a media e a externa não apresentam entre si, nenhuma linha de demarcação e devem ser confundidas e conside- 
radas como formando uma unica camada, a camada externa. A parecle venosa é constituida somente por 2 tunicas: a interna e a externa.

1. $\left.{ }^{\circ}\right)$ Tunica interna - (A. fig. 5): - Como nas arterias, é constituida pelo endothelio e pela camada conjunctivo-elastico, que aqui é designada de endoveia em lugar de endarteria. Segundo Eberth,

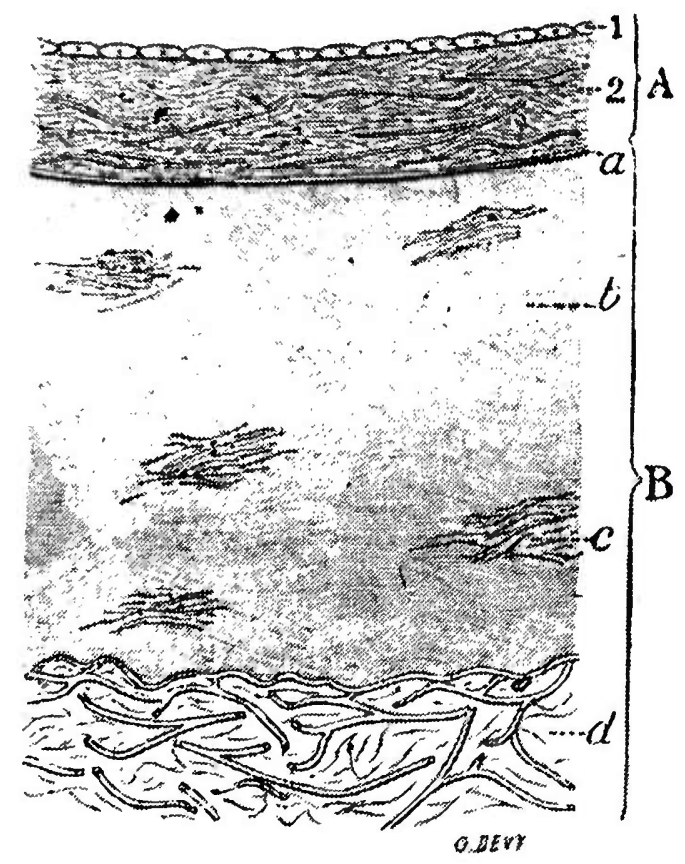

Fig. 5

Estrutura de uma veia. Corte transversal. A, tunica interna com: 1, endotelio; 2, camada conjuntivo-elastica representando a endoveia. $B$, tunica externa, com: a, limitante elastica interna; b, feixes musculares; $c$, feixes conjuntivos; d, parte mais externa da tunica, constituida exclusivamente por tecido conjuntivo.

a endoveia que se acha ausente na cava inferior, faz seu aparecimento na veia iliaca, aumento de espessura até a poplitéa, onde atinge seu. maximo, e decresce em seguida gradualmente nas veias que se seguem.

2. $\left.{ }^{\circ}\right)$ Tunica externa - (B, fig. 5): - Corresponde ás tunicas media e externa das arterias. Compreende 3 ordens de elementos: elementos elasticos, elementos conjuntivos e elementos musculares.

A) Elementos elasticos - Condensam-se na região limitrofe entre a camada interna e a camada media, formando a limitante elastica interna (a, fig. 5). Desta limitante interna partem fibras, que se dirigem para fóra para a superficie externa do vaso, formando em toda a extensão da tunica externa, uma rêde de largas malhas, entre as quais vem se colocar os elementos musculares. Tal é a disposição 
encontrada nas grandes veias. O tecido elastico nas veias de pequeno calibre póde ser excasso ou estar mesmo completamente ausente.

B) Elementos conjuntivos - O tecido conjuntivo é extremamente abundante; póde mesmo, em certas veias onde as fibras musculares não existem, constituir ele só, a quasi totalidade da tunica externa (d, fig. 5). Ele se continua para fóra, como o da adventicia das arterias, com o tecido conjuntico peri-venoso.

C) Elementos musculares - As fibras musculares variam extraordinariamente, em numero e disposição, de acordo com o tipo de veia, isto é, com as veias de pequeno, de meio e de grande calibre. Em resumo, existem 2 grupos de veias: a) veias receptoras, que estão reduzidas a um endotelio repousando sobre uma camada conectivoelastica de um desinvolvimento variavel (veias da dura-mater, piamater, veias da retina, canaes de Brechet dos ossos, veias jugulares etc.). b) veias misculares - que apresentam um maior ou menor desinvolvimento muscular, cujas fibras pódem se dispor em um ou mais planos (circular e longitudinal) (b, fig. 5).

Inervação dos vasos - Procurando esquematizar a questão, devemos saber que os vasos recebém uma dupla inervação: cerebroespinhal e simpatica. Sabemos que o nervo pudendo interno fornece ramos á arteria iliaca externa, que o nervo obturador envia filetes á arteria iliaca interna, que o genito-crural dá ramos á arteria femoral etc.... tal é pois a inervação cerebro-espinhal dos vasos. No que diz respeito a inervação simpatica já a cousa é um pouco mais complexa. Para bem compreendel-a torna-se necessario saber o qué seja o sistema simpatico.

As funções nervosas do organismo são regidas por 2 grandes sistemas: o sistema da vida de relação, responsavel pela execução dos movimentos e pela percepção das excitações externas, e o sistema autonomo ou simpatico (tambem conhecido por sistema grande simpatico, ortosimpatico, sistema nervoso ganglionar, sistema nervoso da vida vegetativa etc.) que regula as funções da vida vegetativa. Anatomicamente considerando, o sistema simpatico apresenta uma parte central e outra periférica. O simpatico central é formado por nucleos ou colunas de celulas distribuidas ao longo da medula; destes, o que nos interessa no momento, é o que se acha localizado no angulo de união entre o corno anterior e o posterior da medula e que se extende desde a parte media do $8 .^{\circ}$ segmento cervical até o bordo inferior do

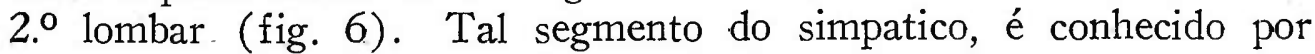
tractus intermedius-lateralis, corno lateral da medula ou simpatico medular dorso-lombar; é ele que fornece os filetes simpaticos destinados aos vasos.

O simpatico periférico é constituido por uma serie grande de ganglios que se dispõem agora, não mais ao longo da medula, mas sim ao longo da coluna vertebral, formando a chamada cadeia paravertebral ou cadeia latero-vertebral do simpatico, a qual se extende 
desde da $1 .^{a}$ vertebra cervical até a ultima sagrada; é portanto muito mais extenso que o simpatico central que se extende somente de C8 a L" (fig. 7).

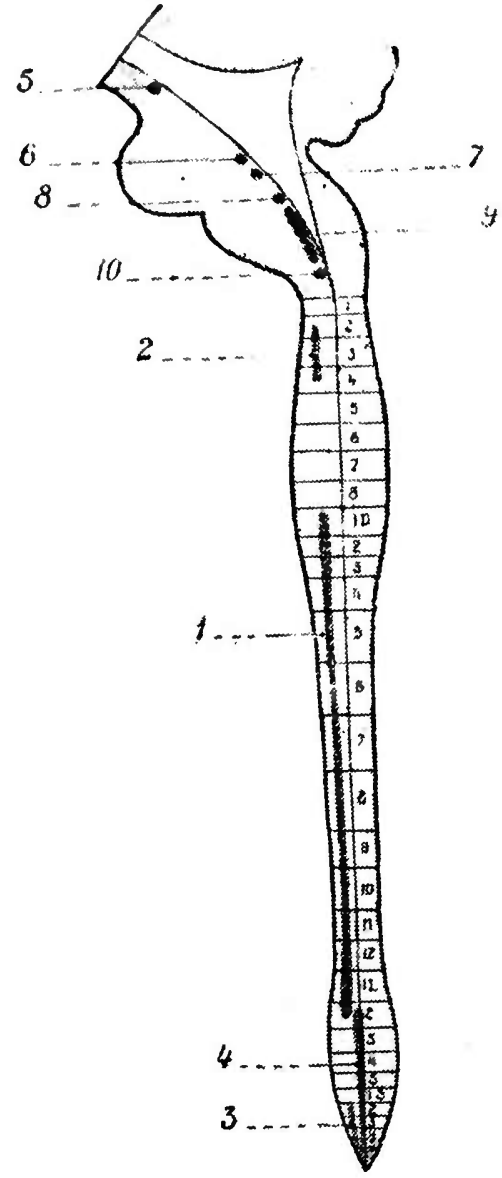

Fig. 6

Simpatico medular. Tractus intermedius lateralis. (1)

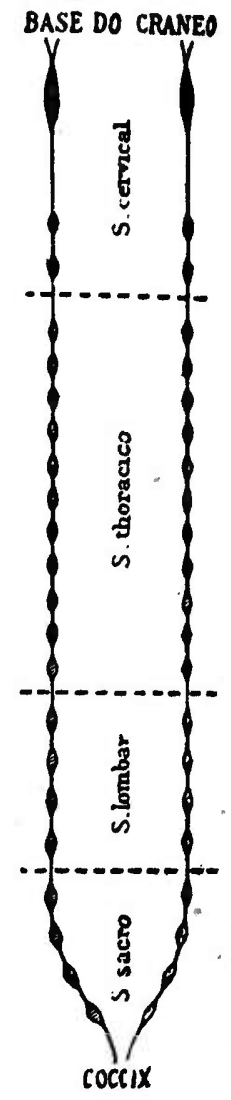

Fig. 7

Simpatico catenario periferico (esquematico)

O simpatico central é pois intramedular enquanto que o periférico é extra-medular, correndo ao lado da coluna vertebral. A figura 6 esquematisa em 1, o segmento simpatico que constitue o tractus intermedio-lateralis. A figura 7 representa o simpatico periférico, com seus 4 segmentos: cervical, toracico, lombar e sagrado.

Os dois sistemas simpaticos, central e periférico, não são porém isolados, acham-se em comunicação pelos ramos comunicantes brancos os quais são constituidos por fibras de mielina conhecidas pela designação de fibras pré-ganglionares. As fibras pré-glanglionares não apresentam porém um trajéto unico: umas se extendem do tractus intermedios-lateralis, saíndo pelo corno anterior, ao ganglio simpatico da cadeia simpatica latero-vertebral e aí se extinguem; outras não se interrompem neste ganglio, continuam seu trajéto para 
irem se terminar entrando na constituição do plexo solar, do plexo mesenterico, do plexo hipogastrico etc... (fig. 8, em traço cheio).

Por sua vez, dos ganglios simpaticos da cadeia simpatica laterovertebral, saem outras tantas fibras agora sem mielina, conhecidas por fibras post-ganglionares ou fibras de Remak (fig. 8, em pontilhado), as quais constituem os ramos comunicantes cinzentos que

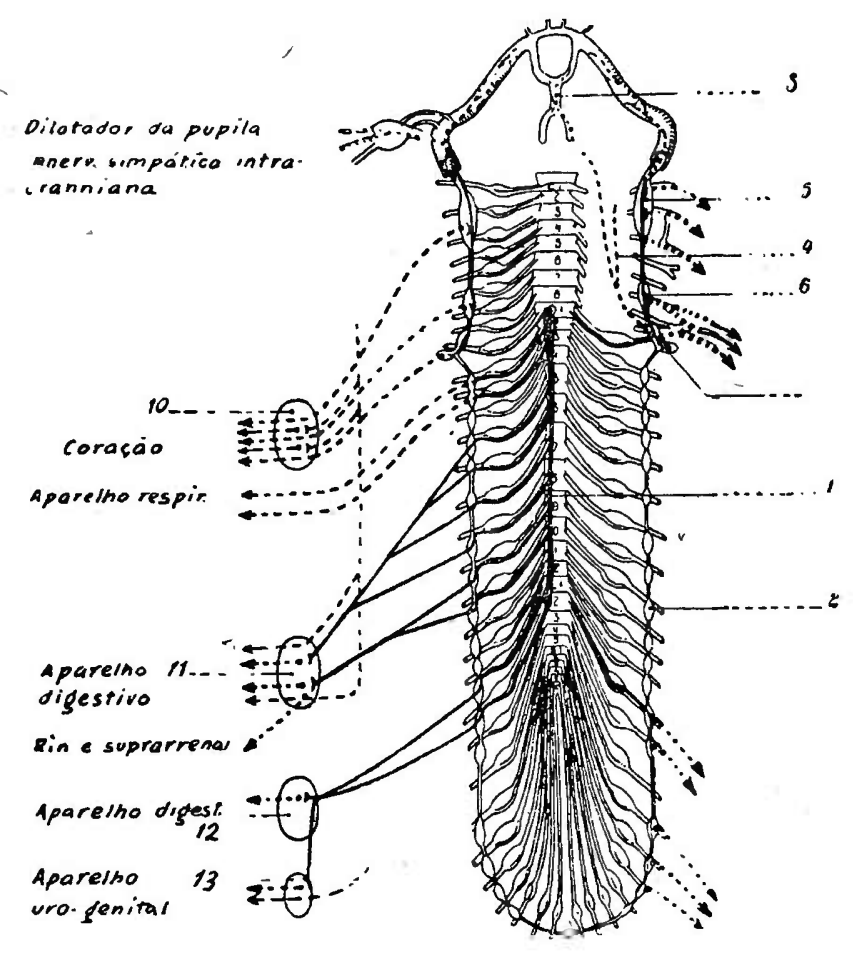

FIG. 8

Sistema simpatico (ésquematico

unem os ganglios simpaticos da cadeia latero-vertebral ao sistema nervoso cerebro espinhal, se prolongando pelos nervos raquidianos até a extremidade; são pois estas, fibras nervosas simpaticas que inervam os vasos.

Analisando a figura 9 entenderemos melhor a questão: vemos as 2 raizes, anterior e posterior do nervo raquidiano ( 1 e 2 ), o ganglio raquidiano na raiz posterior (3), o nervo mixto (4), as fibras pré-ganglionares (12) formando o ramo comunicante branco, comunicando o tractus intermedio-lateralis com o ganglio simpatico periférico, e finalmente, as fibras post-ganglionares (13) se extendendo entre o ganglio simpatico periférico e o nervo raquidano para então se prolongar no interior deste nervo, até a extremidade.

O trajéto do filete simpatico destinado aos vasos, é pois o seguinte: originado no tractus intermedius lateralis, sae da medula pela raiz anterior pelo ramo comunicante branco, por meio do qual chega ao ganglio simpatico periférico. Sae daí pelo ramo comunicante cinzento até alcançar o nervo raquidiano, por dentro do qual vae ter aos vasos. 
O simpatico central é inacessivel ao cirurgião, o mesmo não se diga do periférico, que é hoje frequentemente extirpado nas operaçoes de gangliectomia, como veremos adiante.

As arterias têm uma rêde nervosa na adventicia e outra na camada media; em sua grande maioria são fibras amielinicas. Geralmente se aceita que a maior parte das fibras nervosas terminam

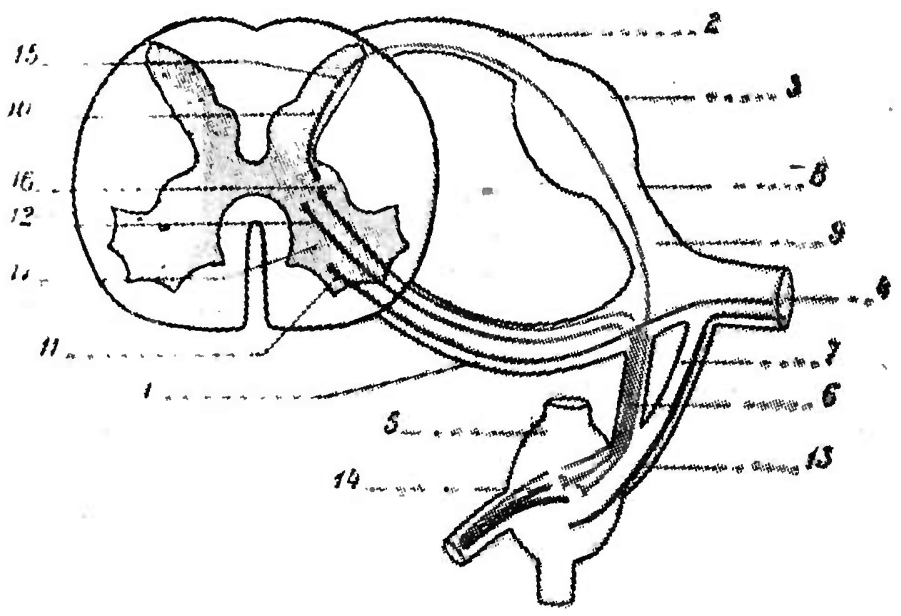

FIG. 9

Esquematisação das raizes raquidianas. 1, raiz anterior. 2 , raiz posterior. 3, ganglio raquidiano. 4, nervo misto. 5, ganglio simpatico. 6, ramo comunicante branco. 7, ramo comunicante cinzento. 8 , fibra sensitiva somatica e sua celula ganglionar. 9, fibra sensitiva simpatica. 10, fibra vasomotora (fibra centrifuga). 11, fibra motora radicular anterior. 12, fibra simpatica pre-ganglionar. 13, fibra simpatica post-ganglionar (para o nervo misto). 14, fibra sim patica post-ganglionar. 15, corno posterior. 16, corno lateral, séde da zona motora simpatica. 17 , corno anterior.

nas celulas musculares lisas da parede arterial. Recentemente alguns cirurgiōes tem sustentado, para explicar fenomenos aparentemente paradoxais, que devem existir centros ou grupos de celulas ganglionares na adventicia das arterias.

Conhece-se desde muito tempo a existencia de terminações sensitivas nas paredes das arterias; podemos mesmo encontrar verdadeiros corpusculos de Pacini. Todas estas terminações sensitivas que se encontram sistematicamente na adventicia, constituem um aparelho nervoso (sic) que controla a circulação nos diferentes territorios do organismo, de acordo com as necessidades locais. Desempenham pois um papel importantissimo, já que sua irritação por processos inflamatorios, dá lugar ao angioespasmo reflexo. Uma vez de posse destes conhecimentos sobre a inervação dos vasos, estamos aptos para entender perfeitamente a questão da

Vasomatricidade e função vasomotora do simpatico - Os vasos sanguineos do organismo humano modificam constantemente seu calibre de acordo com as necessidades gerais (termo-regulação e equilibrio da pressão arterial) e as exigencias locais (atividade 
glandular e muscular, metabolismo tissular). Esta função, que se conhece com o nome de vasomotricidade, se realisa em parte mediante os influxos do sistema simpatico e em parte mediante a intervenção de fenomenos quimicos cuja essencia intima nos é ainda desconhecida. Apezar da cirurgia só ser possivel no primeiro, é indispensavel conhecer todo o mecanismo da vasomotricidade para compreender as modificações fisio-patologicas que determinam as operações de gangliectomia simpatica.

Vaso-constricção - A constricção das arteria é regida de forma predominante pelo sistema nervoso simpatico. $\mathrm{E}$ ' assim que, a secção da medula acima do primeiro segmento dorsal produz uma queda acentuada da pressão arterial por. vasodilatação geral, e a excitação eletrica do extremo distal da medula seccionada, eleva rapidamente a dita pressão por vaso-constricção. A queda da pressão é tanto menos acentuada quanto mais baixo é o nivel da secção medular e desaparece por completo quando é praticada abaixo do segundo segmento lombar. Deduz-se pois, que todos os vasos do organismo mantem seu tonus graças a estimulos centrais vindos do segmento medular interposto, entre o $1 .^{\circ}$ segmento dorsal e o $2 .^{\circ}$ lombar, isto é, do já conhecido tractus intermedius-lateralis.

A excitação eletrica das raizes anteriores da medula, desde a 8. ${ }^{\text {, }}$ cervical até a $2 .^{\mathrm{a}}$ lombar (os limites superior e inferior das colunas simpaticas intramedulares, são variaveis, póde subir até a 1. ${ }^{\text {a }}$ C. e descer até a 4. ${ }^{\mathrm{a}} \mathrm{L}$ ), determina uma vaso-constricção periférica e um ligeiro aumento da pressão arterial, emquanto que as raizes posteriores réspondem com uma vaso-dilatação em seu respectivo territorio periférico; fica assim bem evidenciado, que as fibras simpaticas vaso-constrictoras abandonam a' medula pelas raizes anteriores, como aliás já tivemos ocasião de dizer. Analogo fenomeno verifica-se mediante a excitação eletrica dos ramos comunicantes brancos dos ganglios simpaticos periféricos e dos ramos comunicantes cinzentos.

Sob o ponto de vista da cirurgia do simpatico é fundamental saber que os ganglios da cadeia simpatica latero-vertebral deixam de funcionar, desde que suas conexões com a medula tenham sido seccionadas. Também é importante o conhecimento de que, a extirpação dos ganglios $2 .^{a}$ dorsal, estelar e intermedio, suprime no homem, os reflexos vaso- motores e pilo-motores e a secreção sudoral da cintura escapular, do membro superior, do pescoço e da cabeça. -Por sua vez a extirpação do segmento superior da cadeia lombar, os suprime em todo o membro inferior. As operações de gangliectomias simpaticas, que tomaram grande incremento nestes ultimos tempos, se baseiam justamente na extirpação destes ganglios; são pois assentadas em uma base fisiologica indiscutivel.

Convem ainda recordar que as arterias têm fibras sensitivas que correspondem ao sistema espinal, cujas terminações parecem ser 
cxcitadas fisiologicamente pelas diferenças de tensão a que estão submetidas suas peredes. Por outro lado Leriche já fez notar, ha muitos anos, que basta tocar ou beliscar a adventicia de uma arteria para que apareça imediatamente uma contração local mais ou menos clemorada. Si a excitação é persistente, produz-se o estado patologico descrito durante a ultima guerra sob o nome de estupor arterial. Nos estados patologicos os processos inflamatorios ou trombosicos excitam anormalmente as terminações sensitivas e como respostas a estas excitações aparece o espasmo local, que desempenha um papel importantissimo na patogenia da trombo-angeite obliterante.

Vaso-dilatação - A vaso-dilatação produz-se principalmente pelo relaxamento do tonus vaso-constrictor. Si o tonus desaparece por completo, como sucede após as gangliectomias simpaticas, estabelece-se a vaso-dilatação paralitica. Porém, alem desta vasodilatação paralitica, existe uma vaso-dilatação ativa, cujo mecanismo é muito mais complexo; o exemplo mais tipico da vasodilatação ativa é o que aparece nos fenomenos inflamatorios. A existencia de fibras nervosas vasodilatadoras é cada ves mais discutida e hoje só é aceita a existencia de fibras nervosas vaso-dilatadoras e assim mesmo com certas reservas, ao nivel da corda do timpano, do pequeno nervo petroso, do lingual e do nervo pudendo; suas fibras iriam terminar respectivamente na glandula sub-maxilar, na parotida, na lingua e nos corpos cavernosos. Se tais fibras na realidade existem, elas pertencem ao sistema para-simpatico e portanto nunca se acham em relação com as cadeias ganglionares do simpatico.

Os nervos espinaes têm, sem contestação, uma ação vaso-dilatadora. A excitação do cabo distal de um nervo seccionado 3 ou 4 dias antes, bem como a das raizes posteriores da medula, determina um maior afluxo de sangue no territorio correspondente á sua inervação.

Motricidade capilar - Afirma Krog que o comprimento total dos capilares de um homem de 50 quilos atinge 100.000 quilometros e sua superficie total é de 6.300 metros quadrados; si se tem em conta que a seu nivel realiza-se não só o intercambio do oxigenio e do $\mathrm{CO}^{2}$, como tambem o de todas as materias organicas e inorganicas, compreender-se-á a enorme importancia que tem suas funções no organismo. De uma maneira geral, póde-se afirmar que a motilidade capilar é um fenomeno independente do sistema nervoso; não existem terminações nervosas nos capilares. De fato, nos animais em que se destróe totalmente o simpatico periférico e todos os nerros espinhais, bem como nos enfermos gangliectomizados, têm se observado que a função dos capilares continua a se processar da mesma forma que no estado normal. Não existe porém, como se poderia pensar, uma anarquia funcional entre os capilares e o resto do sistema vascular. A prova a mais caracteristica da independencia da função capilar se observa ao nivel da péle: assim por exemplo 
basta submergir um braço durante 10 minutos em agua fria, para constatar que ao mesmo tempo que desce o indice oscilometrico evidenciado por uma arterio-constricção - aparece um rubor cujo limite coincide exactamente com o nivel da imersão, o que demonstra que se produzio uma capilaro-dilatação.

$E^{\prime}$ hoje admitido por todos', que a motricidade capilar é regida por determinadas substancias que se acham em circulação, ou são geradas na intimidade do endotelio. E' sabido que a adrenalina provoca a dilatação capilar. A vasopresina (derivada da pituitrina) é capilaro-constritora.

Segundo Gaskell, a substancia vaso-dilatadora, gera-se no interios dos tecidos como resultante directo 'do catabolismo celular. Formam-se assim as metabolitas de Gaskell. Thomas Lewis diz que a substancia vaso-dilatadora é muito semelhante á histamina, razão pela qual a designa de substancia $\mathrm{H}$ em substituição ao de metabolistas.

Estando a péle exposta ao calor, seu metabolismo acelerado aumenta a produção de substancia $H$, ha pois vaso-dilatação e rubor. Pelo contrario o frio, diminuindo o metabolismo celular, reduz a produção de substancia $\mathrm{H}$ e daí contração dos capilares. Si porém o frio é excessivo ele acarreta o sofrimento celular, a substancia $\mathrm{H}$ reaparece em excesso e ao dilatar os capilares, provoca o rubor cianotico. A insolação, a inflamação, diversas substancias quimicas e a isquemia, atuam de forma analoga.

Devemos agora passar em revista os diferentes processos de patologia vascular, ou seja a fisio-patologia vascular, sem o que não poderemos entender o mecanismo intimo de produção das diferentes afecções dos vasos.

\section{CONCEITOS GERAIS SOBRE A PATOLOGIA VASCULAR}

A integridadé dos tecidos do organismo humano é assegurada pela circulação do sangue atravéz das arterias, capilares e veias. As' alterações morbidas que se estabelecem neste circuito, acarretam diversas modificações tissulares cuja importancia varia com a intensidade do obstaculo e com o setor em que recae sua ação.

As alterações circulatorias periféricas são devidas a causas hidrostaticas, mecanicas e funcionais. As primeiras são condicionadas por exemplo pelos estados de hipotensão brusca por vasodilatação no territorio esplancnico; não nos interessam no momento. As ultimas pelo contrario, estão frequentemente associadas em patolagia vascular e portanto seus efeitos se somam. Entre as causas mecanicas agrupamse aquelas que determinam a oclusão ou a obstrução dos vasos sanguineos, seja por factores externos (compressões), seja por fatores internos (embolias, trombose e endangeitis). Entre as causas funcionais acham-se as que derivam da perda das propriedades fisiologicas 
das paredes vasculares (arterioesclerose) ou da exaltação morbida de uma função normal (angiospasmos). Estudaremos sómente os granres problemas gerais relacionados com a patologia cirurgica; consideraremos as seguintes questões: 1) coagulação do sangue, 2) trombose. 3) embolia, 4) edema, 5) circulação colateral, 6) hipohe. mia e hiperhemia, 7) gangrena.

$\left.1 .^{\circ}\right)$ Coagulação do sangue - Os vasos são revestidos internamente por uma camada unica de celulas endoteliais; este endotelio apresenta a qualidade caracteristica de impedir a coagulação do sangue no interior dos vasos. Esta noção é de grande importancia em patologia vascular. Havendo uma solução de continuidade na camada endotelial, verifica-se imediatamente, a coagulação do sangue a esse nivel. Inversamente, é possivel conservar sangue indefinidamente liquido, dentro de um segmento de vaso limitado por 2 ligaduras, desde que o endotelio se mantenha integro. O mecanismo intimo da propriedade anti-coagulante do endotelio é ainda desconhecido.

A coagulação do sangue consiste na formação de fibrina, que se dá graças á transformação do fibrinogenio (elemento contido no plasma) pela trombo-kinase (fermento posto em liberdade pela destruição celular) em presença dos sais de calcio. $\mathrm{Fb} .=\mathrm{Fbgo}+\mathrm{Tkz}+\mathrm{Ca}$ $($ Fibrina $=$ Fibrinogenio + Trombokinase + ions de calcio $)$.

Modernamente com o advento da vitamina $\mathrm{K}$, os conhecimentos sobre a coagulação de sangue, estão no entanto, ligeiramente modificados.

Desta noções sobre coagulação resultam dados interessantes e uteis para cirurgia como o tempo de coagulação e os diferentes meios de diminui-lo, e já foi tambem verificado que um dos velhos processos é a injeção de sangue do proprio individuo, a chamada auto-hemo-injeção. A simples passagem do sangue pela seringa e a sua reinjeção na veia de onde foi aspirado já é suficiente para diminuir o tempo de coagulação.

2. ${ }^{\circ}$ Trombose - E' a coagulação intravascular de uma parte ou de todos os componntes do sangue. E' o processo o mais importante e o mais dificil de explicar de toda a patologia vascular; póde ser observado nas arterias, veias, capilares e no corảção. Diversos são os fatores que entram na genese do processo, os principais são :

a) diminuição da velocidade da corrente sanguinea;

b) lesão do endotelio vascular;

c) modificações fisico-quimicas do plasma sanguineo e dos elementos figurados do sangue. 
a) Diminuição da velocidade da corrente sanguinea - As experiencias classicas de Zahn, Eberth e Schimmelbusch, mostram a influencia da diminuição da velocidade da corrente sanguinea como causa determinante da produção de trombos: quando se examina ao microscopio um capilar de grande diametro, uma venula ou uma arteriola, observa-se em sua parte central uma coluna liquida muito densa, de côr vermelha, constituida especialmente por hematias, que avançam velozmente pelo eixo da corrente sanguinea. Esta corrente é tão rapida que é materialmente impossivel reconhecer as hematias. Reconhece-se porem os leucocitos que caminham muito mais lentamente pela zona periférica rasando o endotelio vascular. Se agora, mediante um artificio qualquer, feduz-se a velocidade da corrente sanguinea, observa-se que os globulos vermelhos se destacam nitidamente uns dos outros mas não abandonam a parte axial da corrente; pelo contrario na zona plasmatica aumenta consideravelmente o numero de leucocitos ao mesmo tempo que se nota uma acentuada migração de plaquetas sanguineas, que abandonam a camada central para se aproximarem das paredes. Produz-se a chamada migração das plaquetas.

Ao lado da diminuição da velocidade da correnté sanguinea Aschoff creou a concepção nova dos rodamoinhos. Este fenomeno é consequente ás diversas barreiras interpostas na direção da corrente sanguinea e é visto ainda no ponto de desembocadura de uma corrente de menor velocidade numa outra de maior e nosangulos de bifurcação. Assim os esporões arteriais e as valvulas venosas seriam condições mecanicas favoraveis á formação dos rodamoinhos.

b) Lesão do endotelio vascular - Se n'uma arteriola que sofreu a mesma diminuição da velocidade circulante se produz uma pequena lesão com a ponta de uma agulha, nota-se rapidamente um acumulo de plaquetas sanguineas de mistura com globulos brancos e vermelhos, que adere á zona traumatizada do endotelio. Entre este fenomeno e o descrito anteriormente existe uma diferença fundamental; na marginação das plaquetas cada um dos elementos conserva sua independencia e permanecerá rodeado de uma camada plasmatic periférica; no acumulo traumatico as plaquetas se conglutinam umas com as outras e o conjunto adere á parede do vaso. No final de algumas horas acha-se constítuido o trombo branco parietal. . Si a ferida é muito mais extensa e permite a saída de sangue para o exterior, se assiste á formação de um coagulo extravascular, que é atribuido á primeira vista, como o causador da detenção da hemorragia. Comtudo, retirado este coagulo externo não se repete a hemorragia; é que dentro da luz vascular forma-se tambem um trombo que é o que na realidade impede a perda desangue. Si a ferida ou o traumatismo-mecanico ou quimico são de maior monta, o trombo branco parietal continúa seu desenvolvimento e se transforma em um trombo obliterante. Convem saber que a fibrina não intervem em nada 
na formação do trombo branco ou trombo de conglutinação; ella só se encontra presente nos trombos vermelhos ou trombos de coagulação.

Os processos degenerativos como a arterioesclerose determinam tambem as lesões da intima, com as seguintes fases no processo:

a) depositos de colesterina na intima abaixo do endotelio,

b) calcificação destas areas,

c) necrose das mesmas,

d) queda do endotelio por falta de nutrição.

E' necessario que a estes procesos degenerativos' se associem outros fenomenos como a diminuição da velocidade da corrente circulatoria e modificações fisico-quimicas do sangue parà que se verifique a trombose de uma arteria atingida mesmo por grave arterioesclerose.

c) Modificações fisico-quimicas do plasma sanguineo e dos elementos figurados do sangue - Todas as intervenções cirurgicas, assim como os traumatismos, determinam modificaçốes intensas no plasma e nos elementos sanguineos. Ha uma diminuição dos globulos vermelhos em consequencia da perda maior ou menor de sangue. Surge leucocitose. Muito frequentemente ha um aumento do numero de plaquetas; esta plaquetose aparece entre o $4 .^{\circ}$ e o $10 .^{\circ}$ dia e desaparece bruscamente nos doentes onde se desenvolve uma trombose; tal fato se explica por grande retenção de plaquetas pelo trombo. Normann fez destes fenomenos um sinal diagnostico de trombose. Por outro lado verificam-se tambem alterações plasmaticas que favorecem a tendencia aglutinante das plaquetas. E' assim que se observa no periodo posogeratorio um aumento do fibrinogenio capaz de ascender a $40 \%$ da cifra primitiva; concomitantemente surge um aumento de velocidade de eritro-sedimentação e uma maior viscosidade do sôro e do plasma. Muitas destas modificações sanguineas citadas, surgem egualmente, à escarlatina, à erísipela, à febre reumatica, às infecções piogenicas. A concomitancia do processo infeccioso é tão frequente na trombose, que chegou Cruveilhier a afirmar que "não existe trombose sem infecção", o que naturalmente não constitue uma regra para todos oscasos. Fica agora facil de compreender o mecanismo que determina o aparecimento de trombose no periodo posoperatorio: modificações fisico-quimicas do plasma e dos elementos sanguineos, agregadas a uma diminuição da velocidade sanguinea motivada pelo choque cirurgico ou pela anestesia raquidiana.

Alguns autores teriam dado importancia a questão da carga eletronegativa das plaquetas que tem seu ponto iso-eletrico entre 5,4 e 4,7 sendo o plasmo igualmente negativo. Toda a vez que o plasma sofrer modificações no sentido da positividade (acidose) ha diminuição da carga negativa das plaquetas e conglutinação.: 
Resumindo, a trombose não é devida a um agente unico exclusivo, mas sim á combinação de pelo menos 2 dos fatores trombogenos já conhecidos; assim: diminuição da velocidade sanguinea + lesão clo endotelio vascular, diminuição da velocidade sanguinea $\div$ alterações fisioquimicas do sangue etc... Entre as inumeras causas determinantes de diminuição da velocidade sanguinea encontram-se as molestias cardiacas e o choque operatorio; entre as determinantes lesões do endotelio temos as causas mecanicas, inflamatorias e degenerativas; como causas mecanicas citamos os traumatismos (trombose da axilar pelo uso de muletas), as feridas, as ligaduras cirurgicas; as inflamatorias são consequentes ás endocardites, arterites e flebites; finalmente as degenerativas são devidas aos processos de arteriosesclerose. Como causas responsaveis pelas alterações sanguineas fisico-quimicas, citamos o choque operatorio e as infecções.

Evolução do trombo: O trombo uma vez formado sofre uma evolução que é variavel para cada caso, assim pode ele ter o tamanho reduzido por perda de sôro sanguineo ficando uma pequena porção de coagulo e fibrina intimamente aderente a uma das paredes do vaso, retraindo-se e permitindo a formação de um espaço livre entre o trombo e a parede do vaso.

Reabsorção: Uma outra ocorrencia tambem muito frequente é a reabsorção parcial ou total do trombo que é devida a dois fatores principais: ao amolecimento e á atividade leucocitaria; o amolecimento se verifica na parte central do trombo e é provavelmente devido. a falta de nutrição. Os leucocitos tem grande papel na destruição do trombo onde são encontrados em grande numero.

Organização: A outra modalidade de evoluçãa do trombo é a sua organização que se verifica toda a vez que não ha reabsorção do mesmo. No ponto em que ha aderencia dotrombo á parede vascular verifica-se uma invasão do endotelio vascular e de fibroblastos que crescem e se propagam no interior do-coagulo e este tecido conjuntivo jovem muito vascularizado se transforma a pouco e pouco em fibrocitos e fibras conjuntivas. Com o tempo este tecido torna-se denso e fibroso e a luz do vaso desaparece.

Ocasionalmente, mas, raramente o sangue pode cavar um canal atravéz do trombo que assim torna-se recanalisado.

3..$^{\circ}$ Embolia - E' a oclusão de um vaso sanguineo por um corpo solido, liquido ou gasozo, arrastado pela corrente circulatoria. Estes corpos circulam livremente até que chegam a um vaso de calibre menor que seu proprio diametro, e então se detêm e actuam como uma rolha obstructiva. Os trombos desprendidos de seu leito são os que constituem a imensa maioria dos embolos solidos. Em uma proporção muito menor se encontram as embolias parenquimatosas, entre as quais agrupam-se as de celulas placentarias durante a gravidez, a de fragmentos de tumores malignos que invadiram a luz vascular e a de fragmentos de figado ou de medula ossea após os grandes traumatismos. As embolias parasitarias e a de corpos ex- 
tranhos ocupam o ultimo lugar. As embolias mais perigosas são as venosis: os trombos formados nas veias se desprendem parcial ou totalmente, quando ha um aumento brusco da velocidade da corrente sanguinea. Arrastado pela corrente venosi chega ao coração direito que o lança na arteria pulmonar em uma de cujas arborizações ele vae se deter. E' o acidente muito conhecido do operado, que no $80^{\circ}$ ou $10 .^{\circ}$ dia, após um esforço qualquer, cae morto instantaneamente ou vem a falecer poucas horas mais tarde, pela chamada forma asfixica de embolia pulmonar. Se o embolo é pequeno produz-se somente um infarto pulmonar, campo ótimo para o desinvolvimento de um futuro abcesso pulmonar por infecção do infarto.

As embolias arteriais são devidas em geral a processos trombosicos desenvolvidos no coração esquerdo, na aorta ou em um de seus ramos. As mais frequentes são as consequentes aos trombos cardiacos das endocardites agudas ou crônicas. Os trombos se detem com predileção no ponto em que as arterias e bifurcam; é assim que a terminação da aorta, da iliaca primitiva, da femoral e da poplitéa, são os pontos em que as embolias se localizam com mais frequencia.

As grandes embolias periféricas levam o membro rapidamente a gangrena massiça. As pequenas embolias periféricas se detêm ao nivel das arteriolas determinando tão somente pequenas zonas de isquemia. Existem finalmente 2 tipos de embolia que convem conhecer :

a) Embolia retrograda - $\mathrm{O}$ embolo chegado na veia cava superior, passa diretamente na cava inferior para deter-se no territorio das supra-hepaticas, ‘das renais ou das iliacas; é devido a um aumento de pressão no coração direito como sucede por exemplo na insuficiencia tricuspide.

b) Embolia paradoxal - E' a que se verifica quando existe a persistencia do buraco de Botal (34 a 45\% segundo Marchand e Klob) ; o embolo consegue então passar da grande circulação venosa para a grande circulação arterial sem atravessar o territorio da circulação pulmonar.

4..$^{\circ}$ Edema - O edema considerado sob o ponto de vista cirurgico póde apresentar as seguintes varidades:

1. $\left.{ }^{\circ}\right)$ Post-traumatico;

2..$^{\circ}$ Flebitico e varicoso;

3. $\left.{ }^{\circ}\right)$ Neuropatico e trofoedema;

$4^{\circ}$ ) Elefantiasis nostras;

5. ${ }^{\circ}$ Elefantiasis exotica.

O edema post-traumatico - que sobrevem após fraturas bem ou mal reduzidas, por contusão articular, entorse, apresentam todos os mesmo mecanismo, e apezar de se ignorar o processo tissular intimo, 
ele está em relação direta com as perturbações vaso-motoras locais ocasionadas pelo trauma.

Estes fenomenos foram vistos e confirmados por Leriche quando estudou as variações oscilometricas após os acidentes.

Frequentemente as modificações vaso-motoras que surgem após os traumas são entretidas por uma terapeutica inadequada, aparelho de gesso muito apertado ou posição viciosa do membro. Desta terapeutica mal conduzida resultam perturbações funcionais caracterizadas sempre pelo edema, rarefação, disturbios vaso-motores e dolorosos e muitas vezes contraturas musculares.

Temos então o chamado edema post-traumatico de Secretan quando predomina o edema.

Passemos agora a outra variedade de edema ou o flebitico que apresenta duas condições diferentes:

$\left.1^{\circ}\right)$ Periodo de estado de flebite aguda $e$

2.0) Sequela de uma flebite passada.

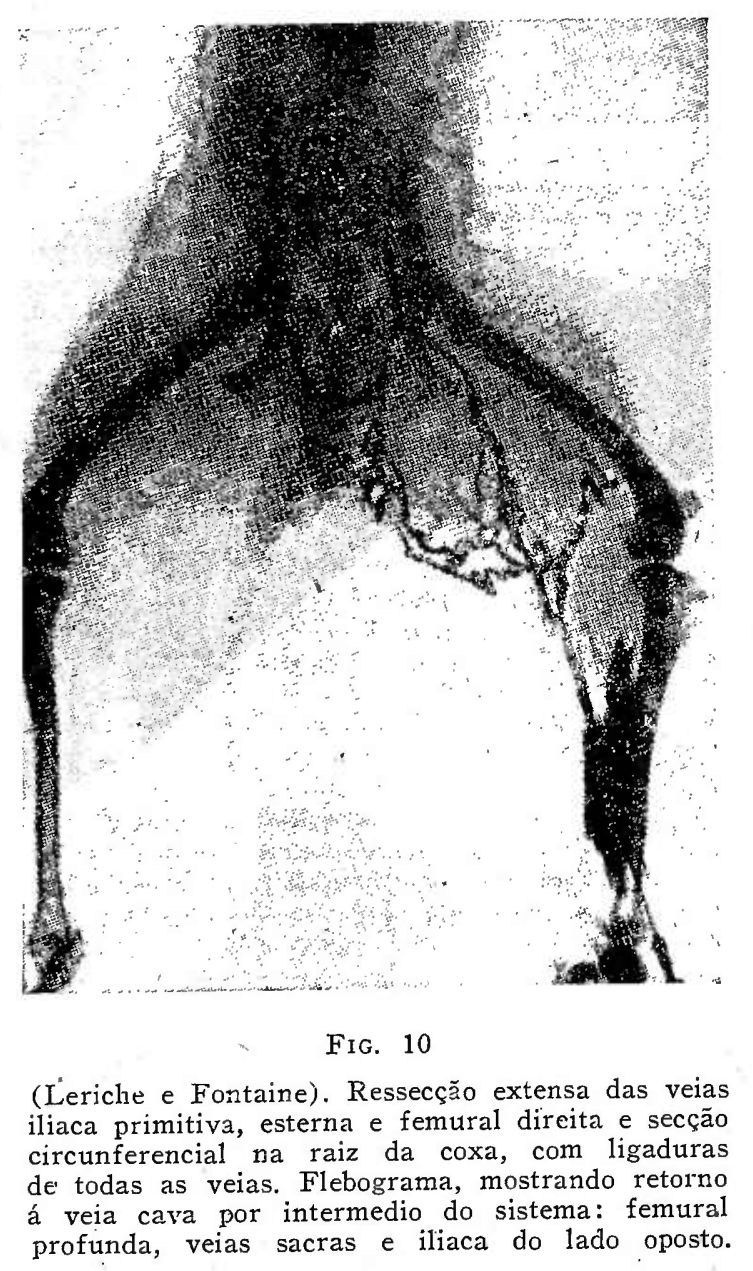

Ainda não se, conhece perfeitamente bem o mecanismo do edema na flebite, e isto em parte. porque não ha documentação anatomopatologica da flebite no homem. Não se sabe se na flebite do mem- 
bro inferior a trombose venosa se inicia na raiz ou na extremidade do membro. Será a trombose venosa segmentaria como o é a arterial, on será total.

O estudo experimental não elucida muito porque os animais são muito refratarios as flebites (Fig. 10).

Querendo estudar a questão do mecanismo do edema na obstrução venosa Leriche e A. Jung fizeram no cão obliterações sucessivas das safenas interna eexterna, femurais superficial e profunda, das veias iliacas interna e externa e até do segmento inicial da cava inferior obtendo com todo este obstaculo mecanico um edema de natureza transitoria de duração de oito a vinte e dois dias (Fig. 11).

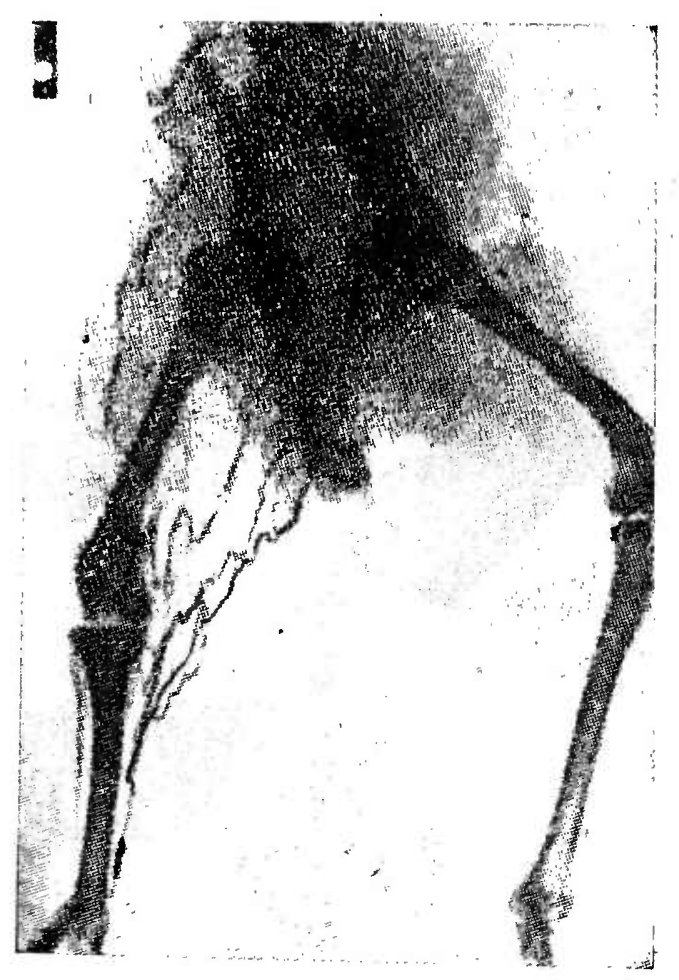

Fig. 11

Leriche e Fontaine. Ressecção das veias iliacas primitiva e esterna da femural e da śafena direitas, até a raiz dos dedos do pé. Incisão circunferencial na raiz da coxa interr mpendo todas as veias superficiaes. Flebograma dez meses mais tarde. Enchimento imediato da veia cava inferior pelas anastomoses do sistema sacro com a iliaca do lado oposto e pelas veias sub-cutaneas abdominais.

Com Souza Pereira, Leriche fez extensas resecções venosas e radiografando tempos mais tarde verificava que a circulação se processava regular e normalmente por intermedio de colaterais.

Os AA. citados além das resecções venosas esclerosavam os segmentos restantes da veia. A circulação se processava por intermedio das sacras e da iliaca primitiva do lado oposto e nos casos de ligadura da cava inferior na sua origem ela se fazia por intermedio das sub-cutaneas abdominais (Fig. 12). 
Ao lado destas resecções e tromboses venosas extensas foram feitas resecções linfaticas amplas e aqui ainda o edema foi transitorio. O edema experimental só foi conseguido a custa de extensas mutilações como a secção circunferencial do membro.

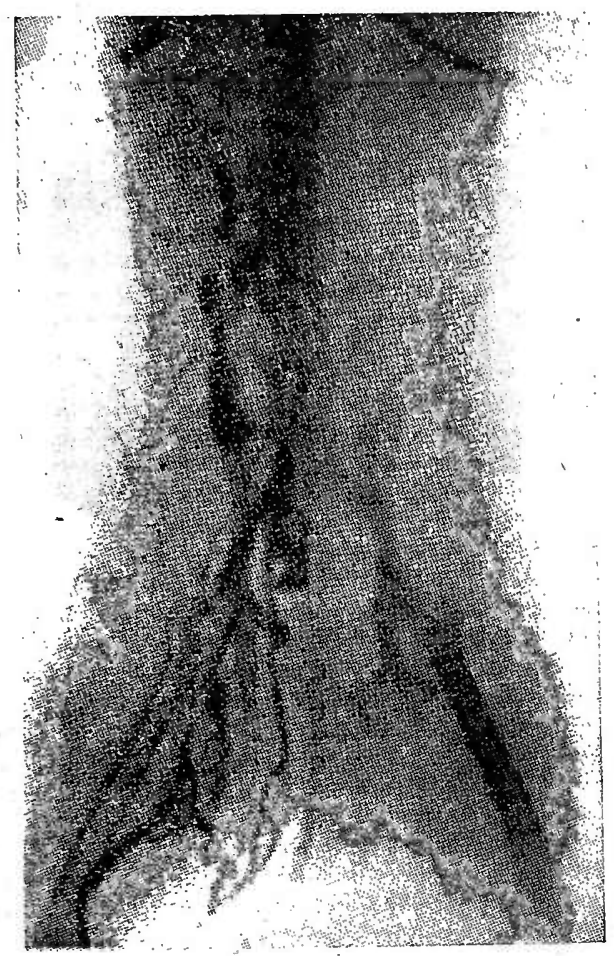

FIG. 12

Leriche e Fontaine. 19-9-1933. A esquerda, resecção de $4 \mathrm{cms}$. da veia femural, a partir da arcada de Falopio. A direita esclerose do mesmo segmento. 17-10-1933. Á esquerda, reseç̧ão da veia iliaca primitiva; á direita, esclerose do mesmo se'gmento entre duas ligaduras. 20-1-1934. Trombose da veia cava inferior (origem). Oito meses mais tarde, flebograma. O contraste (torotraste) atinge facilmente, e, por intermedio de calibrosas veias da parede abdominal, a veia cava superior. Não ha estase e a circulação de retorno não é impedida.

Vê-se portanto que ao lado do fator obstrutivo, ha um outro elemento que predomina no quadro clinico do edema flebitico e, que é sem duvida alguma, o fator nervoso, dadas as dôres que se verificam neste quadro e os resultados beneficos obtidos com o tratamento orientado neste sentido, como o das infiltrações ganglionares conı novocaina.

As malhas do tecido celular e do tecido intersticial dos orgãos constituem cavidades virtuais através das quais circula por -capilaridade o chamado liquido intersticial; Achard deu ao conjunto destas cavidades o nome feliz de sistema lacunar. O liquido instersticial que se caracteriza por sua riqueza em cloretos e sua pobreza em albu- 
mina, banha constantemente os elementos celulares e assegura sua mutrição. Sua circulação estabelece-se entre os capilares arteriais, clonde procede, e os capilares venosos e linfaticos, onde é reabsorviclo. O edena é a resultante de um estado de pletora na circulação intersticial. Sabendo que o sistema lacunar escôa-se atravez dos capilares venosos e linfaticos, facilmente se deprende que a oclusão de qualquer destas duas circulações vae dar lugar a um edema de origem mecanica. O tipo classico destes edemas é dado pela ligadura da veia principal de um membro e pela obstrução cicatricial dos grandes coletores linfaticos, tal como se observa a meúdo após 0 esvaziamento ganglionar da axila por cancer da mama. A fisiopatologia dos edemas é bastante complexa e até hoje não se encontra bem esclarecida; para não nos alongarmos muito vamos deixar de lado a questão da pressão osmotica, proteinas, cristaloides, etc. Note-se porem que grande numero de lesões vasculares, devido às perturbações acarretadas na circulação sanguinea, são acompanhadas de edema.

$\left.5^{\circ}{ }^{\circ}\right)$ Circulação colateral - E' muito conhecida a classica' e antiga classificação de Cohnhein em arterias terminais e colaterais. A oclusão das primeiras, cujo tipo classico é dado pelas divisões da arteria pulmonar, acarretaria fatalmente a isquemia e a gangrèna do territorio correspondente; a oclusão das segundas, seria pelo contrario perfeitamente suportada pelos tecidos. Em suas grandes linhas gerais esta classificação é verdadeira, ela sofre porem uma serie grande de excepções cujo conhecimento é altamente interesante em patologia vascular. Assim por exemplo, a cirurgia nos ensina, que emquanto a ligadura da iliaca externa ou da femoral acima de sua bifurcação são perfeitamente suportadas pelos pacientes, a ligadura da femoral abaixo da femoral profunda é comumente seguida de grangrena do memibro. Este fenomeno, aparentemente paradoxal, tem uma explicação muito facil. No primeiro caso a circulação se estabelece prontamente entre a iliaca interna ou hipogastrica e a femural profunda, por intermedio das arterias gluteas, isquiatica e obturadora; em seguida caminha o sangue pela femural profunda e pelas arterias perfurantes indo novamente se lançar no tronco da femural abaixo da ligadura. A este tipo de circulação colaterál deu Porta, onome de circulação colateral diréta. Comtudo a patologia vascular veio nos mostrar outro tipo de circulação colateral que escapa á classificação de Cohnheim. Nos processos de arterio-esclerose ou de trombo-angeite obliterante, as arterias principais se encontram não raro, completamente ocluidas, sem que no entretanto surja 0 mais leve indicio de gangrena. E' forçoso pois aceitar que nestes casos a circulação colateral não se estabelece pelas anastomoses arteriais mas sim pelas arteriolas pré-capilares, pelos minute vessels de Lewis. Constitue este tipo de circulação colateral, a chamada circulação colateral indiréta. 
$\mathrm{Na}$ circulação colateral arterial diréta o restabelecimento da circulação é rapido e completo. Observa-se no maximo nas primeiras 24 ou 48 horas consecutivas á ligadura, uma hipotermia do membro, findo este prazo a temperatura cutanea equilibra-se com a do lado oposto. Fenomeno analogo observa-se com a onda pulsatil e em consequencia com o indice oscilometrico e com a pressão arterial. No caso da circulação colateral indiréta, por mais amplas que estejam "satisfeitas as necessidades sanguineas dos tecidos, não se observa nunca o retorno da onda pulsatil nem da oscilometria. A tensão da circulação colateral pré-capilar apezar de poder alcançar valores muito elevados não chega emcondição alguma a igualar a de um membro são; ela apresenta em suma um restabelecimento lento e inconpleto. Por outro lado o estudo dos trombo-angeiticos nos permite afirmar que a circulação colateral pré-capilar faz-ze de forma sumamente lenta: se a evolução morbida é demorada, o enfermo conserva a integridade de seus tecidos mesmo quando ha oclusão da iliaca primitiva; pelo contrario as poussées agudas determinam fatalmente o aparecimento de fócos isquemicos e. não raro grangrenas.

Estudando-se experimentalmente a circulação colateral constata-se que os vasos que contribuem a formar o novo circuito, dilatamse e se tornam muito compridos; verifica-se egualmente uma verdadeira hipertrofia das paredes vasculares. $\mathrm{Ha}$ pois uma verdadeira adaptação funcional. Junto a esta hipertrofia dos vasos pré-existentes, produz-se uma neoformação vascular mais ou menos intensa. (Fi. 13).
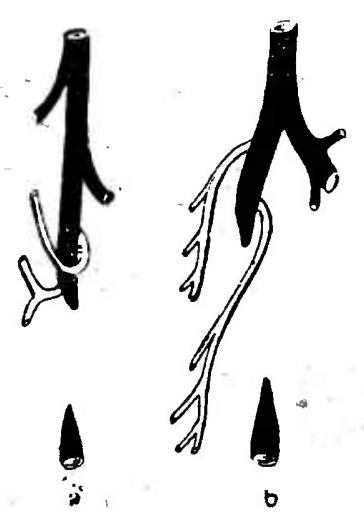
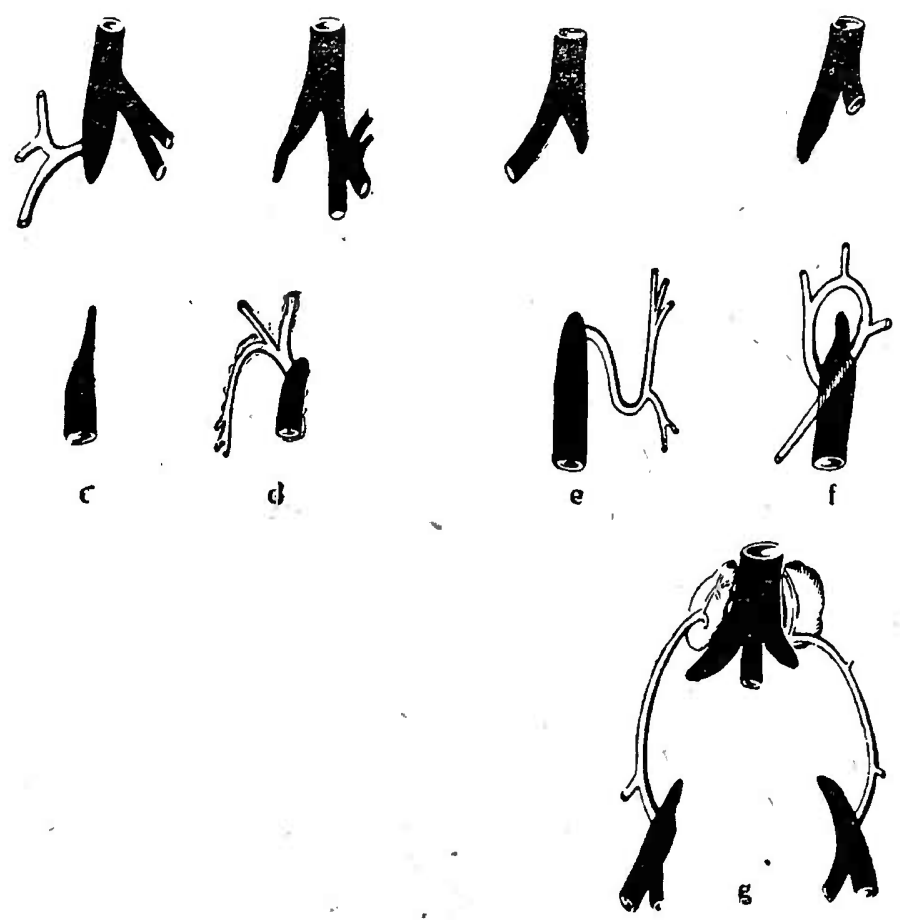

FrG. 13

Iwànow (in Hermet Junior). Desenvolvimentı dos vasos néoformados, que partem aas extremidades caudal e cranial dos vasos ligados. (Esquematico). 
E' admitido hoje em dia como de indiscutivel valor no aparecimento la circulação colateral, do estado da pressão arterial e da tensão local. Isto deve ser aceito porque na realidade os vasos submetidos a uma sobrecarga tem forçosamente que se dilatar.

O mecanismo fisio-patologico responsavel pela constituição da circulação colateral constitue assunto interessantissimo mas um tanto complexo e extenso, não cabendo portanto na explanação rapida que estamos fazendo sobre o assunto. Entretanto devemos nos lembrar, de que o principal fator fisio-patologico favoravel ao desenvolvimento da circulação colateral é a perturbação do metabolismo celular, consecutivo á isquemia ou á hipohemia. A resultante desta perturbação dos tecidos é a libertação de substancias vaso-dilatadoras, que facilitam a circulação sanguinea abrindo os canais pré-formados, e aumentam a pressão da arteria principal do membro (Fig. 14).

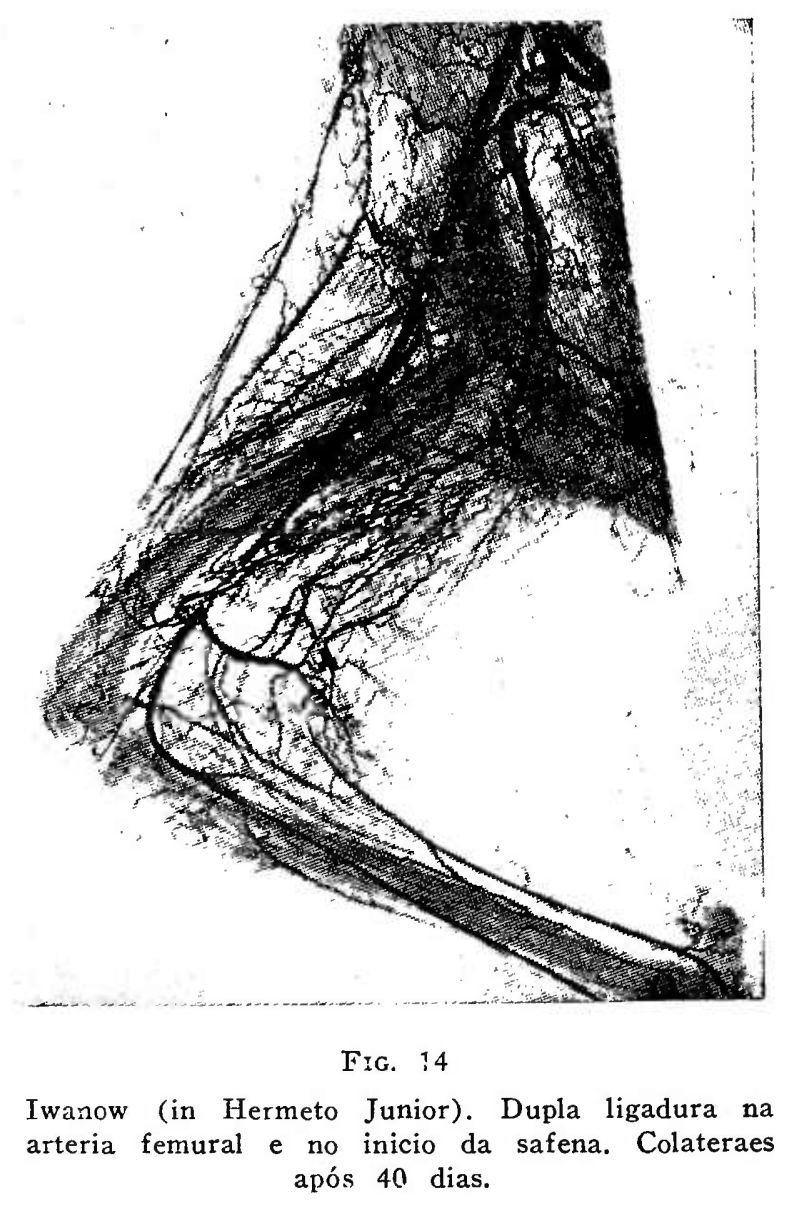

Os tecidos são tão sensiveis a hipoemia que as substancias vasodilatadoras serão libertadas até ao momento em que a corrente circulatoria colateral fôr exatamente equivalente á encontrada nơ membro antes da sua oclusão.

Terminando podemos dizer que inumeros são os fatores que favorecem e determinam o desenvolvimento da circulação colateral. 
$1^{\circ}$ ) Calibre e situação do vaso sanguineo obstruido.

$2^{\circ}$ ) Tipo de obstrução brusca ou lenta;

3. $\left.{ }^{\circ}\right)$ Gráu de viscosidade sanguinea;

$\left.4 .^{\circ}\right)$ Fatores vaso-motores.

O conhecimento do estado circulatorio do membro é valiosissimo, e orienta em muito o cirurgião quanto ao exito de sua intervenção; é medido, na clinica, pela oscilometria e pela arteriografia. (Figs. 15 e 16). As variações do debito sanguineo são controladas

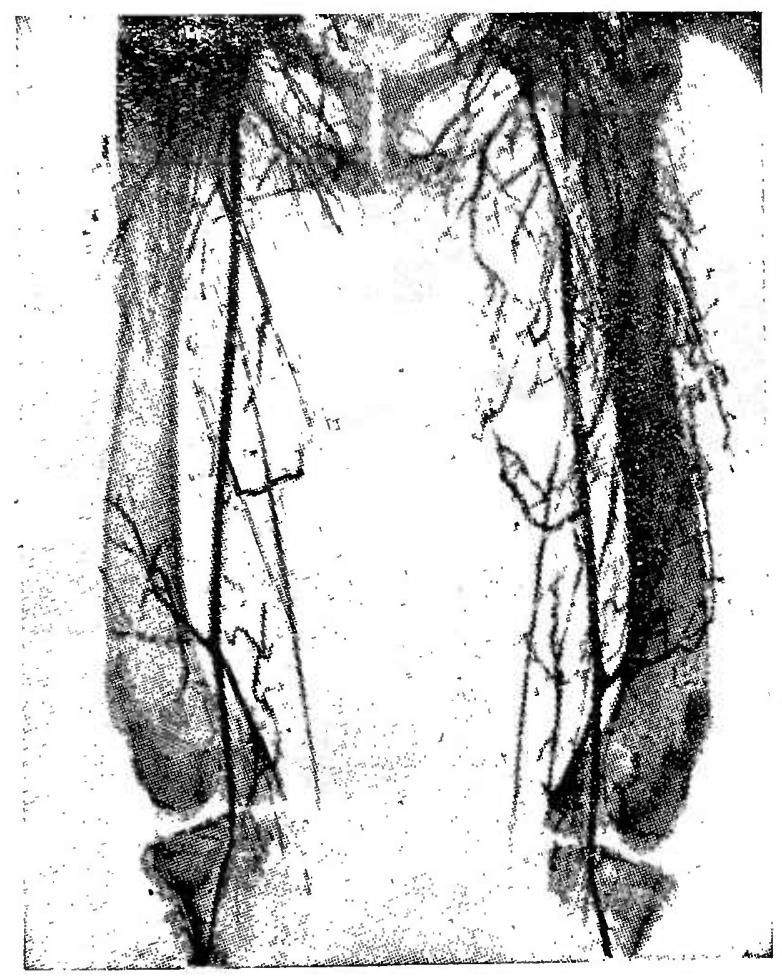

FIG. 15

Iwanow (in S. Hermeto Junior). O lado esquerdo da figura é correspondente ao membro testemunha. Dc lado direito foi feita a ligadura $(x x)$ da arteria femural. Radiografia seis meses após mostra desenvolvimento evidente das vias colateraes do lado ligado.

pelo -sistema endocrino simpatico associado ao vascular e mais as necessidades tissulares, este conjunto todo, constitue no homem um sistema de auto-regulação bastante perfeito.

O equilibrio periférico póde ser rompido igualmente por causas hidroestaticas, mecanicas e funcionais. Tanto as causas mecanicas como funcionais determinam perturbaçóes vasculares perifericas como a hipoemia, isquemia e hiperemia.

\section{6. ) Hipoemia, isquemia e hiperemia:}

a) Hipoemia - Representa a diminuição do debito sanguineo oxigenado. Ela determina nos tecidos um estado de sofrimento que 
os leva seja á hipotrofia, seja á atrofia, isto dependendo do gráu de diferenciação de suas celulas. Os tecidos e os orgãos mais diferenciados serão os primeiros a apresentarem as consequencias. Distinguem-se 2 variedades de hipoemias: arterio-capilar e arterial.

a) Hipoemia arterio-capilar: Exige muitos anos para determinar lesões troficas de importancia e sua resultante final é quasi sempre a atrofia com transformação esclerosa. O exemplo mais tipico é dado pela esclerodermia.

b) Hipoemia arterial: Observam-se nos hipoplasicos è nos membros qua ficam paraliticos como sequela de paralisia infantil. Nestes individuos, a péle insuficientemente irrigada, defende-se mal

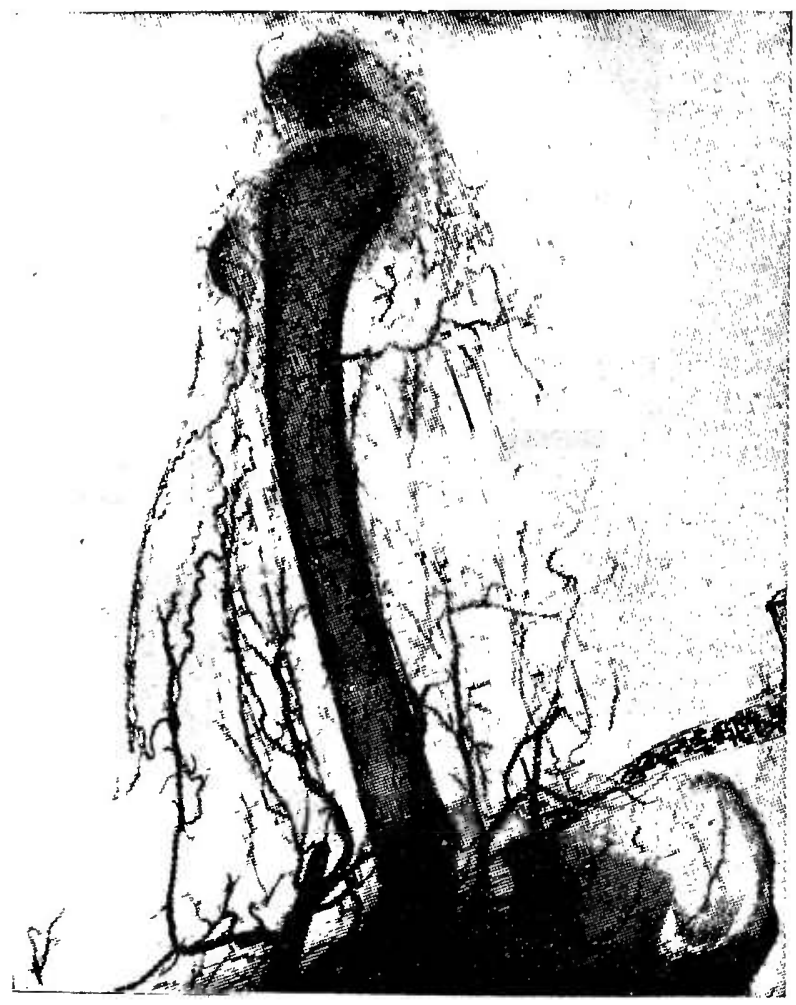

FIG. 16

Iwanow (in S. Hermeto Junior). Arteria da coxa de cãc, seis meses após embolisação "in vivo" com parafina, da arteria femuarl e seus ramos. Gangrena e eliminaçāo da perna.

contra os traumatismos e as fortes quedás de temperatura, observando-se então bastante frequentemente, lesões troficas e ulceras do pé ou da perna.

Eguais perturbações pódem ser verificaads nos aneurismas arteriais difusos dos membros e nos periodos avançados da arterioesclerose, e da tromboangeite obliterante.

b) Isquemia - A intervenção total da circulação arterial produz a anemia local conhecida desde Virchow com o nome de isquemia. De uma maneira geral, a isquemia póde, assim como a 
hipoemia, ser de origem arterio-capilar ou arterial. A primeira é devida a espasmos vasculares e são sempre transitorias; é o que se verifica por exemplo no sindrome de Raynaud e como sintoma prémonitor na trombo-angeite obliterante dos membros superiores. A segunda, é quasi sempre difinitiva e determina alterações por vezes gravissimas nọs tecidos; tal é por exemplo a isquemia por obstrução - de uma arteria terminal como a pulmonar, a lienal ou a renal, que levam sempre ao infarto anemico. As causas mais habituais de isquemia são a trombose, a endangeite e a embolia.

c) Hiperemia - E' um processo que resulta de um aumento de sangue oxigenado ao nivel das arterias e capilares, ou de sobrecarga de sangue com gaz carbonico. A hiperemia póde depender de modificações arteriaes, capilares e venosas; as duas primeiras caracterizam-se pelo aumento de sangue oxigenado, a terceira pela sobrećarga de sangue oxicarbonado.

O tipo classico de hiperemia arterial é dado pelos processos inflamatorios localizados, especialmente se são de forma aguda; é a hiperemia a responsavel pelo classico rubor inflamatorio. $O$ segundo tipo é representado pela hiperemia neuro-paralitica consecutiva á secção dos nervos vaso-constrictores: a secção do simpatico cervical do coelho na altura do ganglio superior determina um rubor da orelha com marcada dilatação da arteria do pavilhão. Estados semelhantes obtem-se diariamente com a cirurgia do simpatico como veremos mais tarde.

A hiperemia capilar é bastante comum, é vista por exemplo na molestia de Weir-Mitchell onde vemos aqui e ali a coloração cutanea arroxeada e sensação de calor; é o que tambem se verifica nos exantemas das molestias eruptivas.

A hiperemia venosa, tambem chamada passiva, deriva de um obstaculo ao retorno do sangue venoso, que tanto póde recair sobre o coração como sobre as veias periféricas. Si as hiperemias ativas não determinam nunca alterações tissulares, as hiperemias venosas são pelo contrario sempre prejudiciais aos tecidos. A primeira alteração é a dilatação e o estiramento dos vasos venosos, que tomam o tipo varicoso; produz-se a transudação serosa e a diapedese dos globulos vermelhos; á primeira atribue-se o edema e á segunda as pigmentações cutaneas por transformação da hemoglobina extravasada. As celulás sujeitas apezar de se encontrar em excesso não tem a quantidade de oxigenio suficiente, e sim acha-se sobrecarregado com $\mathrm{CO}^{2}$. As celulas que mais sofrem são as mais diferenciadas, as do sistema nervoso central. As celulas dos orgãos secretores diminuem rapidamente sua função, o que se verifica comumente no figado e nos rins; se a asfixia local se prolonga, iniciam-se os fenomenos regressivos, caracterizados pelas degeneraçóes e pela atrofia celular. Pelo contrario, o tecido conjuntivo, cujas exigencias vitais são muito reduzidas, prolifera ativamente e enche os vazios deixados pelas celulas parenquimatosas, levando a uma verdadeira hiperplasia. 
A resultante, final da hiperemia venosa é a atrofia perenquimatosa com esclerose intersticial ou massiça. Estes fenomenos não são exclusivos dos orgãos abdominais, cujo exemplo mais tipico é dado pela cirrose cardiaca do figado. Alcança todos os tecidos do organismo; a varicocele produz comumente uma transformação esclerotica do testiculo e as varizes dos membros inferiores acarretam a fibrose do tecido celular sub-cutaneo com ulceração da péle.

$\left.7 .^{\circ}\right)$ Gangrena - Os processos de hipoemia ou de isquemia levam frequentemente os tecidos ao processo de necrobiose. Por necrobiose entende-a a morte lenta das celulas por insuficiencia circulatoria; as celulas em estado de meiopragia continuam porem a participar, si bem que fracamente, nos intercambios, graças aos liquidos que lhes chegam por difusão dos tecidos vizinhos, e vão então passando pelos diversos estadios de degeneração, o que faz com que ao exame microscopico aparecam desprovidas de suas caracteristicas estruturais e tintoriais. Se o processo se acentía temos a etapa final - a necrose. Aqui a morte celular é brusca tal como se observa nas congelações e nas queimaduras ou sob a ação dos acidos e bases fortes bem como a eletricidade. $\mathrm{Na}$, pratica, entende-se porem por necrobiose, a degeneração anatomica completa das celulas, visivel somente ao microscopio e por necrose a morte celular extensa que se faz aparentemente á simples 'vista.

Gangrena é a necrose dos tecidos que estão em contáto com o ar. Com a morte dos tecidos continuam porem os processos metabolicos, se desenvolvendo de imediato a ação dos fermentos celulares; produz-se assim a transformação da hemoglobina e uma serie de fenomenos de decomposição que dão ás partes grangrenadas uma côr marron escura ou preta.

E' classico se diferenciar 2 grandes tipos de grangrena: a gangrena sêca e a humida. A primeira se estabelece quando primitivamente se reabsorvem o sangue venoso e o liquido intersticial e posteriormente se produz a dessecação por evaporação cutanea. Os tecidos privados de agua reduzem consideravelmente seu volume, retraem-se, endurecem-se e se apergaminham, tomando um aspecto semelhante ao das mumias do antigo Egypto, razão pela qual dá-se ao processo o nome de mumificação.

Quando nos tecidos necrosados não se produz a dessecação primitivas, a humidade tissular favorece o desenvolvimento dos germens da putrefação cadaverica que são os que determinam o aparecimento da gangrena humida. Finalmente se ha a proliferação de germens anaerobios (Vibrião septico de Pasteur, B. perfringens, B. welchii, B. histolyticus e B. oedematiens) desenvolve-se a variedade de grangrena humida conhecida por grangrena gazosa, onde então a necróse é produzida pelas toxinas microbianas que coagullam as albuminas celulares e trambosam os vasos sanguineos. de 2 tipos:

Quanto ao processo etio-patogenico as gangrenas

podem ser 
a) Gangrena por lesão da celula e consequente a ação dos agentes termicos, físicos, quimicos e toxicos sobre o parenquima.

b) A gangrena de origem circulatoria, consequente á isquemia, consequentes a procesos que agem mecanicamente, ou determinam as modificações do debito segundo as condições já conhecidas.

$\mathrm{O}$ estudo intimo do processo de necrose, no seu aspecto fisiopatologico mostra que este processo está em intima relação com áquele do desenvolvimento da circulação de suplencia.

\section{BRUNO ZARATIN}

\section{TABELIÃO DE NOTAS}

\section{Rua Marconi, 100 \\ Telefones $\left\{\begin{array}{r}4-2880 \\ 4-2881\end{array}\right.$}

S. P A U L O 


\section{DR. LAET DE TOLEDO CESAR}

CIRURGIÃO DENTISTA

RAIO X - ULTRA-VIOLETAS - DIATHERMIA - INFRA-VERMELHOS

CIRURGIA DOS MAXILARES - EXTRAÇÕES - CASOS DIFICEIS

CONSULTORIOS: CIDADE

EDIFICIO: S. MANOEL TELEPHONE: 4.7349

$R \cup A M A R C O N I, 138$

ESQUINA: B. DE ITAPETININGA

6. ANDAR

SANT'ANNA: RUA VOL. DA PATRIA, 348 - TELEPHONE: 3.8242

RESIDENCIA: RUA CONS. SARAIVA, 291 - TELEPHONE: $\mathbf{3 - 8 2 9 2}$

Exmo. Snr. Dr. Clineo Paim

\section{CAPITAL}

Acuso recebida sua lestimada carta de 30 deste, na qual o ilustre colega solicita a minha opinião (aliás sem nenhum merito ou valor cientifico) a respeito da cirurgia como tratamento ida paradentose.

Sempre bisonho na especialidade lardua que abracei de cirurgia buco facial, não me assiste o direito de fazer consideraçãiss sobre o tratamento da paradentose, mesmo aquele que deva ser feito por processo cirurgico.

Cumpre-me entretanto, dizer com toda a lealdade profissional que, 'se por um lado obtive resultados satisfatorios nalguns casos de paradentose, ou molestias que para mim se assemelhavam a poliartrite alveolo dentaria feitos por mim por processo cirurgico, outros redundaram senão em verdadeiro fraciasso, pelo menos em uma inutilidado de ação.

Em vista do presado colega haver iniciado sua referida carta salientando que me escrevia na qualidade de fabricante do preparado "Pyorrhon", destinado ao tratamento da piorréa alveolo dentaria e das gengivites, quero desassombradamente e com o maior entusiasmo de quem observa cuidadosamente, faz experiencia e registra, felicitar 0 colega e a medicina pelo valor do mesmo preparado em qualquer tratamento das mucosas da boca. Posso the afirmar que tenho observàdo casos surpreendentes com o seu indispensavel "Pyorrhon".

E' com prazer que valho-me da oportunidade para cumprimenta-lo cordialmente 


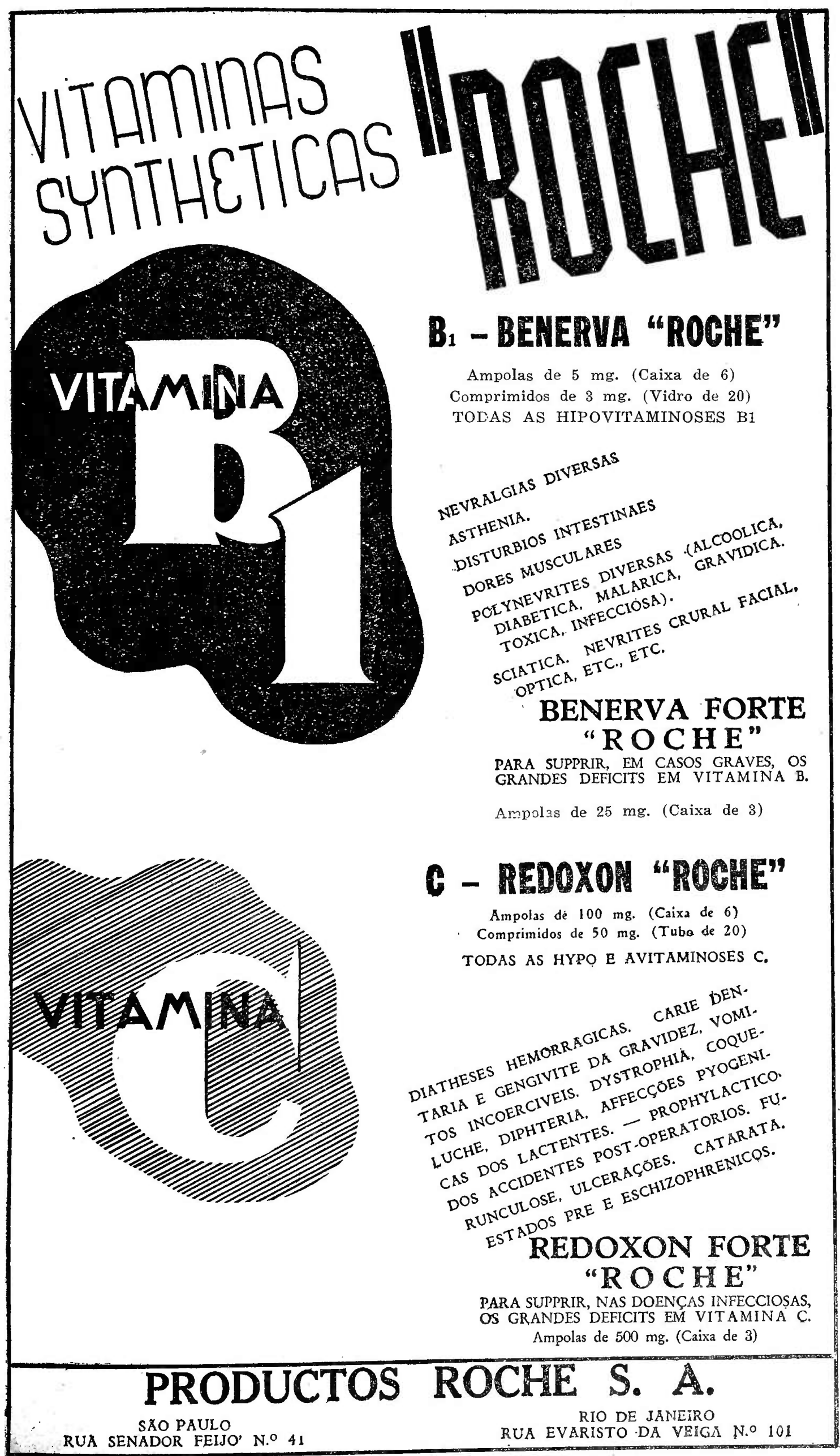




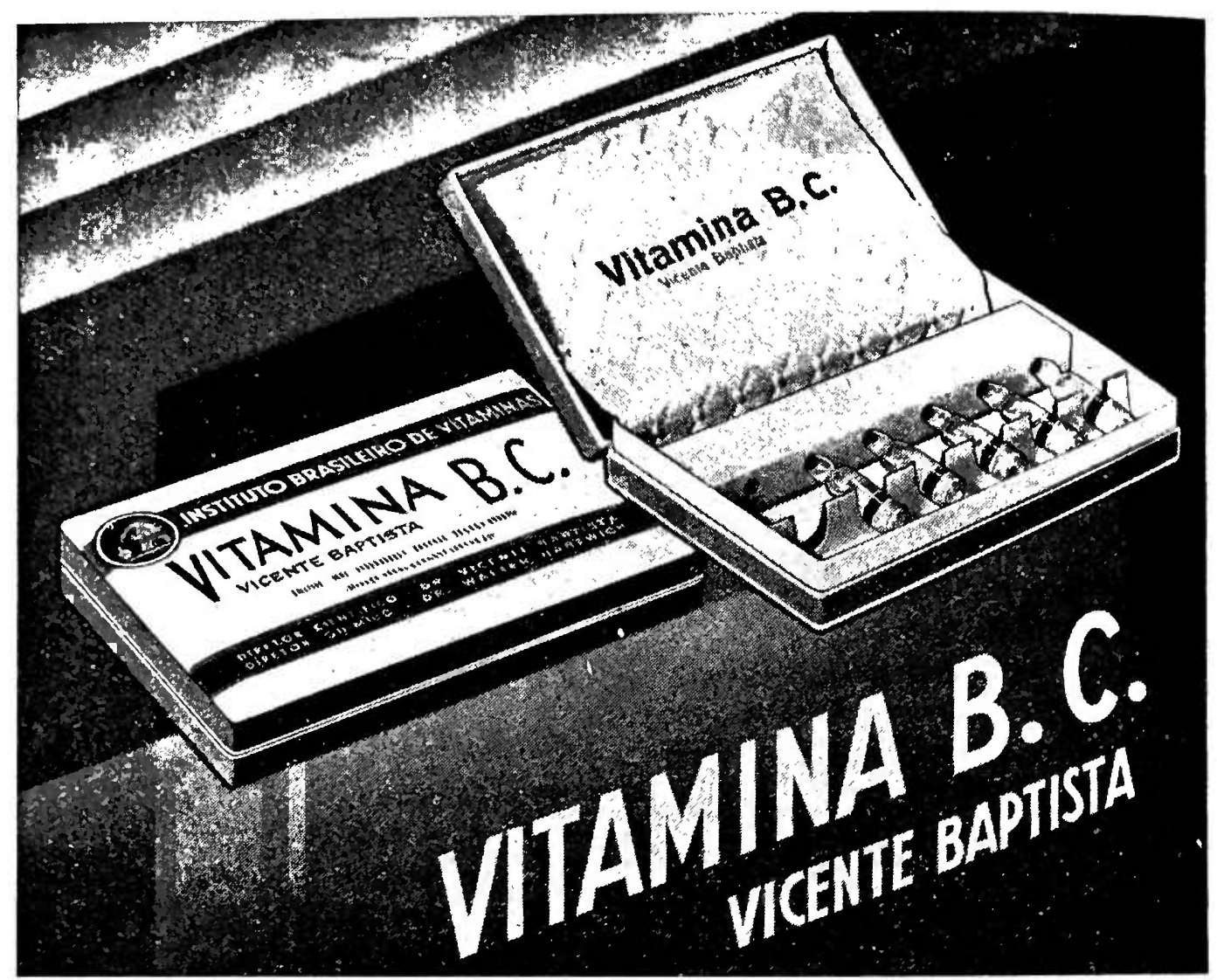

Composição:

Tiamina 0,001 - Acido l-a corbico 0,10

Veiculo q. s. p. 2 c. c.

\section{Indicações :}

Vitaminas B. e C. são indicadas nas avitaminoses B1 e C tipicas (beri-beri e escorbuto) e suas formas frustas, bem como nas carencias mixtas; beriberi nautico, hidropsia epidemica e polinevrite escorbutica.

No terreno pediatrico Vitaminas B. C. encontram amplissimo campo de ação: anorexia, prisão de ventre, parada de peso rebelde a dietoterapia classica, distrofias de causa obscura, sensibilidade ás infecções, afecções alergicas. nervosismo, diatese hemorragica, etc. $O$ diabetes tambem agradece as vitaminas B. C., bem como a insoniạ.

Modo de usar:

CRIANÇAS: Uma injeção cada dois dias, por via intramuscular ou intravenosa. ADULTOS: Uma injeção diariamente. VIA ORAL: 2 drageas por dia.

\section{INSTITUTO BRASILEIRO DE VITAMINAS}

\section{Consultor-Cientifico:}

\section{Dr. Vicente Baptista}

Rua Maria Paula, 124 Filial no RIO DE J A N E I R : R u a C onceição, 80-A

Tecnico-Chefe:

Dr. Walter Hartwich - Caixa Postal, 847 - SÃO PAULO 